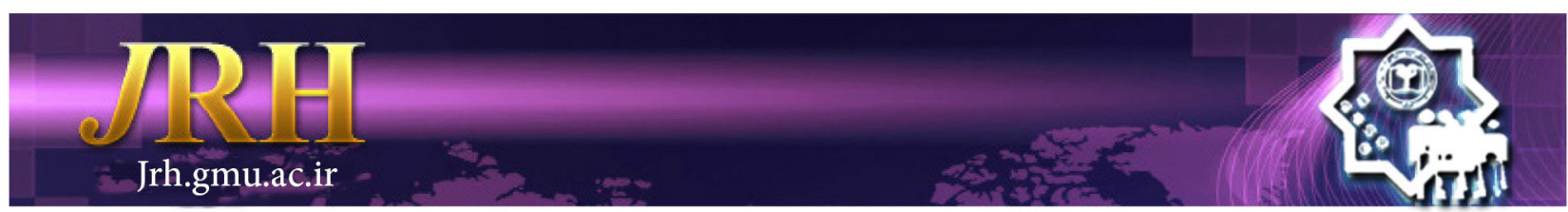

\title{
The relationship of emotional well-being with women's characteristics suffering from breast cancer
}

Elham Pazouki Toroudi ${ }^{1}$, Somayyeh Kazemian ${ }^{2}$

\author{
Journal of Research \& Health \\ Social Development \& Health Promotion \\ Research Center \\ Vol. 8, No. 3, May \& Jun 2018 \\ Pages: 226- 233 \\ DOI: 10.29252 /jrh.8.3.226 \\ Original Article
}

1. Department of Psychology, Faculty of Humanities, Islamic Azad University, Semnan, Iran.

2. Correspondence to: Department of counseling. Faculty of Psychology. Allameh Tabataba'i University. Tehran. Iran

Email: somaye.kazemian@yahoo.com

\section{Received: 10 Dec 2016}

Accepted: 25 Oct 2017

How to cite this article: Pazouki Toroudi E, Kazemian S. The relationship of emotional wellbeing with women's characteristics suffering from breast cancer. $J$ Research

\begin{abstract}
Breast cancer is the most widespread diagnosed illness in women all over the world. The current study's aim is to analyze the relationship of emotional well-being with women's characteristics suffering from breast cancer. This research has been a correlation study. The population studied the women suffering from breast cancer being visited by clinics and hospitals of Semnan state that 250 participants were sampled. Questionnaires have been used for receiving data in this study: The questionnaire of life quality SF- 36 and the questionnaire of temperament and character of Cloninger. The results indicated that the correlation coefficient between emotional well-being and novelty seeking dimensions and vulnerability, cooperativeness, self-directedness is significant. The results from regression analysis proved that the subscale level of novelty seeking, vulnerability, cooperativeness and self-directedness are significant in predicting emotional wellbeing. The results indicate that there is a significant statistical relationship between emotional well-being and characteristic dimensions. According to this relationship we can conclude that the experience of stressful events in life can lead to negative emotions. Thus, providing psychological interventions can reduce the harmful variables of characteristic and increase the well-being in treatment protocol of patients and life satisfaction.
\end{abstract}

Keywords: Breast Cancer, Characteristic Dimensions, Emotional Well-being

\section{Introduction}

Cancer is one of the most widespread diseases in the world which is the cause of uncommon and uncontrollable cell proliferation and creates a malignant neoplasm which different factors are involved in it including genetic, environmental and glandular factors [1]. 30000 Iranian people lose their lives from cancer annually and in fact cancer is the third death factor in Iran [2].

According to world health statistics, breast cancer is the most widespread one among women around the world [3] and it is the second death factor after lung cancer among women. According to American Health Organization statistics breast cancer makes $23 \%$ of cancer in the world and $22.26 \%$ of cancer women cases in Iran. Almost for all individuals suffering from cancer, diagnosing the disease brings frequent problems in personal, family and social aspects of the patients and it triggers feeling of dependency, 
reducing self-confidence and increasing vulnerability and it makes the daily functions and social activities chaotic [4]. Akechi, Nakano and Okaro express the patients' life quality is influenced by diagnosing this illness. In addition, cancer diagnosis and treatment leads to sleep and activity disorder, creating physical and psychological symptoms, social participation and doing personal duties [5].

Life quality is a structure which has been regarded since the second half of the twentieth century. The historical root for applying this expression can be found in Aristotle's classical works. Aristotle says about the relationship between the life quality at the time of happiness and the mental values of individuals [6]. In the last two decades the debate about life quality in the domain of cancer treatments has been expressed seriously. The world health organization6 considers the life quality a multi-dimension concept and defined it as an understanding of each individual from life, values, goals, standards and personal interests. Feeling of security, emotional conflicts, personal beliefs, goals and the level of patience for enduring failures are all effective in determining the understanding type of individuals from themselves (feeling good or bad) [7].

Since emotional wellbeing has been regarded as one of the important factors in life quality and the variables such as cognitive judgments (life satisfaction) and emotional judgments (positive and negative feelings and excitements) are effective in the level of individuals' wellbeing. Therefore, it is crucial to pay attention to the conception of emotional wellbeing [8]. According to Rhine and Deci, there are two main methods for the definition of wellbeing: hedonism 7 and eudemonism 8. Considering wellbeing the same as hedonic pleasure 9 or happiness 10 has a long historical background. For instance, Epicor 11, the Greek philosopher, believed that pleasure is life's main objective. His philosophical hedonism was followed by different scientists; such as Thomas Hobbes 12, British philosopher who believed that happiness is the product of realizing successful wishes or John Stuart Mill 13, a philosopher who believed a true deed is one which promotes the level of happiness in an individual [9].

Most hedonic psychologists believe wellbeing equals to subjective happiness 14 and is related to the pleasure experience versus unhappiness experience. This conception can be known as emotional wellbeing. Emotional wellbeing includes a number of signs expressing presence or absence of positive emotions to life. Emotional wellbeing can be analyzed through three structured scales: The presence of positive emotions (like joy and happiness), absence of negative emotions (like anxiety and disappointment) and life satisfaction [10]. The essence of hedonic absorption describes wellbeing as maximizing the pleasure and minimizing the pain [9]. Frequent researches have been conducted to analyze the effect of personal resources for confronting chronic disease. Most of them emphasize on expectable characteristic factors such as the tendency to optimism, belief in internal source of control and self-efficacy beliefs [11]. A research was carried out by Marshall Gold et al. in 2016 aiming to study symptoms of anxiety and depression after breast cancer surgery and its effect on life quality which indicated the patients had lower scores in life quality (physical, psychological, social and welfare). A higher level of anxiety was along with the presence or absence of depression symptoms with an increase in fear of relapse, hopelessness, uncertainty, loss of control, and a reduction of life satisfaction [12].

Having characteristic considered as a mixture of actions and thoughts, individual's emotions and motivations, there are different elements which make individuals' characteristics. Many researchers believe the presence of personal differences and different characteristic traits highlights the individuals' reactions to the situations and stresses [13]. Cloninger provided a psychological model of characteristic based on seven dimensions consisting of four temperamental dimensions which are permanent in life and three other characteristic dimensions [14]. Four- 
dimensional model of Hippocrates is consistent with ancient model of four humors; individuals are different in terms of melancholic temperament (harm avoidance) 15, choleric (Novelty seeking) 16, sanguine (dependency rewards) 17 and phlegmatic (Persistence) 18 , but presently it is certain that four temperamental dimensions are independent from one another in terms of genetic, and can appear in the form of functional compounds. In addition, the four temperamental dimensions can be regarded in line with four main emotions, fear (harm avoidance), anger (Novelty seeking), love (dependency rewards) and tenacity (Persistence) 19 [15]. Behavioral activation in response to novel Stimuli 20 signifies rewards and release from punishment. Thus, individual's differences are called "Novelty seeking"21 in such capabilities. The individual's differences in the capability of interruption or Inhibitability 22 are called harm avoidance. Cloninger named the individual differences in response continuation after the absence of continued reinforcement reward dependence and called persistence 25 the fourth dimension which lacks subscale.

Cloninger considers three dimensions for temperaments. In this category the selfdefectiveness dimension is based on selfconcept as an independent individual, cooperativeness dimension 27 is based on selfconcept as a part of human world and society and self-Transcendence dimension 28 based on self-concept as a part of the world and its surroundings [16]. In spite of the temperament which belongs to the present differences in automatic emotional reactions and habits, the temperamental dimensions of characteristic deals with individual differences regarding self-images relevant to objectives and values and can change emotional reactions. Three temperament's dimensions include both rational views about individual and nonindividual obstacles and emotional views [17]. Characteristic variables determine the confronting method against stress factors and compatibility way for adapting to them [18]. Studies prove characteristic play the main role in wellbeing [19]. According to the research which was conducted by Sanaat et al aiming to analyze the relationship of characteristic dimensions and cancer, the results indicated the scores of novelty seeking and lower cooperativeness and harm avoidance among cancer patients are significantly higher than normal individuals [20]. As the cancer leads to stress, inability and a decline of life satisfaction, the diagnosed individuals should adapt to the disease requirements and treatments; since it can influence characteristic factors, action and independence of individuals and can change their lifestyle in a way which is a striking reduction is observed in emotional, social, psychological and physical wellbeing. Therefore, according to the mentioned issues, the present study was carried out by the aim of determining the relationship of emotional wellbeing with characteristic dimensions of women suffering from cancer.

\section{Method}

The research method in this study has been correlation. The studied population is women suffering from cancer who were being visited by Semnan province's clinics and hospitals in 2015-2016 and we selected 250 participants by the use of Morgan table as a sample in this research. The sampling method in this research has been stratified random for selecting models. The criteria for study inter: Diagnosing the breast cancer based on pathologic results, all types of mastectomy or lumpectomy surgery on breasts, having no critical condition while filling the questionnaire, volunteer consent. After having the written permission from ethics Committee of Semnan University of Medical Sciences and having permission from hospitals and the relevant departments' authorities (surgery and oncology) and also clinics (ultrasound, surgery) the researcher was present in the research environment and received patients' consent for attending in the study and he began the research. All research samples were assured that the information would be kept in secret and then the questionnaires were submitted to the patients 
or their fellows and were collected after being filled. Two types of questionnaires were used for receiving information in this study. 1) Short form of life quality questionnaire, 36-question (SF36) is valid questionnaire which is used widely for analyzing life quality. This questionnaire itself is a report which was designed by Weir \& Sherbun in 1996 and also it was normalized by Montazeri et al in 2005 [21]. This questionnaire includes 36 questions which are summarized in 8 subscales of multi-material. In the present study the subscale of emotional wellbeing is evaluated by the questions 24-25-26-28-30 and is scored as follows:

In the questions of $24-25-28,0$ is given to number $1 ; 20$ are given to number 2, 40 are given to number 3, 60 are given to number 4,80 are given to number 5, 100 are given to number 6 , and also in the questions of 26-30; 100 are given to number 1,80 are given to number 2, 60 are given to number 3, 40 are given to number 4, 20 are given to number 5 , and 0 is given to number 6. In order to evaluate emotional wellbeing's subscale it is required to add the total relevant questions and then subtract it to the number of questions. 2) The Cloninger's characteristic questionnaire of temperament and character: This questionnaire has been made by Robert Cloninger in 1987 for evaluating temperament, genetic biology and acquired characters. This questionnaire includes 125 questions and each question test is answered by choosing one of the correct or incorrect option and these questions are scored in a form of zero and one. This questionnaire has been normalized by Kaviani et al in Iran and enjoys proper reliability and validity for using in researches. In order to measure the reliability coefficient, the test-retest method was performed which the results indicating strong coefficients for the test are as follows: Novelty seeking $(86 \%)$, harm avoidance $(88 \%)$, award dependence (73\%), persistence $(79 \%)$, cooperativeness $(86 \%)$, and self-directedness (\%90), and self-transcendence $(86 \%)$ [22]. There are week correlations until average correlations (lower than 40\%) between quadruple scales of temperament and triple scales of character, except for correlation of self-directedness and harm avoidance which is higher than $40 \%$. Only the correlation of higher than $40 \%$ between triple dimensions of character is relevant to cooperativeness and selfdirectedness. Analyzing data is conducted based on two methods of descriptive statistics (Central, dispersion indicators and frequency distribution table) and inferential statistics (Correlation, regression) in this study.

\section{Results}

The frequency distribution of studied samples proves that from 250 patients suffering from breast cancer $64.4 \%$ (161 participants) of samples have performed mastectomy treatment and $35.6 \%$ (89 participants) of samples have performed lumpectomy treatment.

Table 1 The average and standard deviation of research variables on both lumpectomy and mastectomy groups

\begin{tabular}{lcccccc}
\hline \multicolumn{7}{c}{ Group } \\
\hline Variables (Subscales) & Mean & $\begin{array}{c}\text { Standard } \\
\text { deviation }\end{array}$ & Number & Mean & $\begin{array}{c}\text { Standard } \\
\text { deviation }\end{array}$ & Number \\
\hline Novelty seeking & 9.36 & 3.47 & 89 & 8.45 & 3.23 & 161 \\
Harm avoidance & 10.50 & 3.84 & 89 & 11.19 & 3.93 & 161 \\
Reward dependence & 8.71 & 2.62 & 89 & 8.28 & 2.49 & 161 \\
Persistence & 3.56 & 1.64 & 89 & 3.59 & 1.68 & 161 \\
Cooperativeness & 16.70 & 3.29 & 89 & 15.75 & 3.95 & 161 \\
Self-directedness & 13.34 & 4.26 & 89 & 12.09 & 4.10 & 161 \\
Self-Transcendence & 10.19 & 2.56 & 89 & 10.00 & 2.62 & 161 \\
Emotional wellbeing & 67.85 & 14.82 & 89 & 64.12 & 15.79 & 161 \\
\hline
\end{tabular}


Table 1 shows the average and standard deviation of characteristic and emotional wellbeing's dimensions of breast cancer patients who performed lumpectomy and mastectomy treatments. The results indicated that the average emotional wellbeing in lumpectomy group is 67.85 with standard deviation of 14.82 and in mastectomy group equals to 64.12 with standard deviation of 15.79 .

Table 2 The normalization test of testing scores' distribution in research variables

\begin{tabular}{lcccccc}
\hline & \multicolumn{3}{c}{ The kolmogorov-smirnov test } & \multicolumn{3}{c}{ The shapiro-wilk test } \\
\cline { 2 - 7 } & statistics & $\begin{array}{c}\text { Grade } \\
\text { release }\end{array}$ & Sig. & Statistics & $\begin{array}{c}\text { Grade } \\
\text { release }\end{array}$ & Sig. \\
\hline Novelty seeking & 0.092 & 250 & 0.000 & 0.966 & 250 & 0.000 \\
Harm avoidance & 0.105 & 250 & 0.000 & 0.964 & 250 & 0.000 \\
Reward Dependence & 0.117 & 250 & 0.000 & 0.971 & 250 & 0.000 \\
Persistence & 0.155 & 250 & 0.000 & 0.940 & 250 & 0.000 \\
Cooperativeness & 0.130 & 250 & 0.000 & 0.968 & 250 & 0.000 \\
Self-directedness & 0.097 & 250 & 0.000 & 0.970 & 250 & 0.000 \\
Self-Transcendence & 0.100 & 250 & 0.000 & 0.977 & 250 & 0.000 \\
Emotional wellbeing & 0.101 & 250 & 0.000 & 0.970 & 250 & 0.000 \\
\hline
\end{tabular}

According to Table 2, scores distribution in research variables are not normal. However, regarding to the proper number of tests and validity of parametric statistics against the violation of this assumption there are no prohibition for using Pearson and Regression's correlation method to test the research assumptions and Table 3 shows the variables' correlation coefficients.

Table 3 The correlation coefficients between research variables

\begin{tabular}{|c|c|c|c|c|c|c|c|c|}
\hline & $\begin{array}{l}\text { Novelty } \\
\text { seeking }\end{array}$ & $\begin{array}{c}\text { Harm } \\
\text { avoidance }\end{array}$ & $\begin{array}{c}\text { Reward } \\
\text { Dependence }\end{array}$ & Persistence & Cooperativeness & $\begin{array}{c}\text { Self- } \\
\text { directedness }\end{array}$ & $\begin{array}{c}\text { Self- } \\
\text { Transcendence }\end{array}$ & $\begin{array}{l}\text { Emotional } \\
\text { wellbeing }\end{array}$ \\
\hline Novelty seeking & 1 & & & & & & & \\
\hline Harm avoidance & $0.239 * *$ & 1 & & & & & & \\
\hline $\begin{array}{l}\text { Reward } \\
\text { Dependence }\end{array}$ & -0.056 & -0.102 & 1 & & & & & \\
\hline Persistence & $-0.190 * *$ & $-0.258^{* *}$ & $0.216^{* *}$ & 1 & & & & \\
\hline Cooperativeness & $-0.156^{*}$ & $-0.199 * *$ & $0.232 * *$ & $0.320^{* *}$ & 1 & & & \\
\hline Self-directedness & $-0.172 * *$ & $-0.274 * *$ & 0.065 & $0.195 * *$ & $0.279 * *$ & 1 & & \\
\hline Self-Transcendence & $-0.196 * *$ & $-0.156^{*}$ & $0.261 * *$ & $0.385^{* *}$ & $0.256^{* *}$ & $0.135^{*}$ & 1 & \\
\hline $\begin{array}{l}\text { Emotional } \\
\text { wellbeing }\end{array}$ & $-0.327 * *$ & $-0.322 * *$ & $0.151^{*}$ & $0.288^{* *}$ & $0.298^{* *}$ & $0.318^{* *}$ & $0.275^{* *}$ & 1 \\
\hline
\end{tabular}

According to Table 3, the correlation coefficients between emotional wellbeing with novelty seeking dimension (-0.327) and harm avoidance (-0.322) in the Alpha level of 0.01 is significant and negative, meaning the increase in novelty seeking and harm avoidance is along with a decrease in emotional wellbeing and vice versa. Also the correlation coefficient between emotional wellbeing with characteristic dimension ofpersistence $(0.288)$, cooperativeness (0.298), self-directedness (0.318) and selftranscendence $(0.275)$ is significant in Alpha level of 0.01 and with characteristic dimension of reward dependence (0.269) is significant in Alpha level of 0.05 . It means the increase in persistence, cooperativeness, self-directedness, self-transcendence and reward dependence is along with increase in emotional wellbeing and vice versa.

In order to predict the emotional wellbeing through characteristic dimension the multiregressions has been used which is $\mathrm{R}^{2}=26.9$ and is significant in Alpha level of 0.05 signifying characteristic dimension of $\% 26.9$ 
from the variation of emotional wellbeing. In Table 4 the regression coefficients' view for predicting emotional wellbeing are detailed through characteristic dimensions as follows.

According to Table 4 the subscales amount of novelty seeking and harm avoidance in predicting emotional wellbeing is negative and the role of cooperativeness and self-directedness is positive and significant. According to Table 6 for each increase unit in novelty seeking there are -0.200 and harm avoidance -0'159 units of standard deviation reduction in emotional wellbeing. For each increase unit in cooperativeness there is 0.123 units and for self-directedness there is 0.172 units in physical health. The other amounts of characteristic dimensions in predicting emotional wellbeing are not significant.

\begin{tabular}{|c|c|c|c|c|c|c|}
\hline & \multirow{2}{*}{$\begin{array}{l}\text { Model } \\
\text { B }\end{array}$} & \multicolumn{2}{|c|}{$\begin{array}{l}\text { Non-standardized } \\
\text { coefficients }\end{array}$} & \multirow[t]{2}{*}{$\begin{array}{l}\text { Standardized } \\
\text { coefficients }\end{array}$} & \multirow[t]{2}{*}{$\mathrm{t}$} & \multirow[t]{2}{*}{ Sig. } \\
\hline & & Standard error & B & & & \\
\hline \multirow{8}{*}{1} & Stable & 52.904 & 6.983 & & 7.576 & 0.000 \\
\hline & Novelty seeking & -0.933 & 0.270 & -0.200 & -3.454 & 0.001 \\
\hline & Harm avoidance & -0.635 & 0.237 & -0.159 & -2.675 & 0.008 \\
\hline & $\begin{array}{l}\text { Reward } \\
\text { dependence }\end{array}$ & 0.215 & 0.356 & 0.035 & 0.604 & 0.546 \\
\hline & Persistence & 0.783 & 0.588 & 0.084 & 1.332 & 0.184 \\
\hline & Cooperativeness & 0.509 & 0.254 & 0.123 & 2.008 & 0.046 \\
\hline & $\begin{array}{l}\text { Self- } \\
\text { directedness }\end{array}$ & 0.638 & 0.220 & 0.172 & 2.899 & 0.004 \\
\hline & $\begin{array}{l}\text { Self- } \\
\text { Transcendence }\end{array}$ & 0.687 & 0.370 & 0.115 & 1.857 & 0.065 \\
\hline
\end{tabular}

\section{Discussion}

The results proved that there is a negative and significant relationship between characteristic factors of novelty seeking and harm avoidance with emotional wellbeing in this research. The yielded results of this research are in line with Van Dijek et al [23], Hosking et al and [24], Spittlehouse [25], Moradimanesh et al [26]. For clarifying this finding we can express as women suffering from breast cancer experience lower positive emotions in emotional wellbeing dimension, they are less likely to be happy. This factor makes the individuals to experience negative emotion, emotional instability, lack of life satisfaction, and rarely express their positive emotions; Therefore, these individuals are usually timid, nervous, shy, doubtful, hopeless, inactive, negative-oriented, pessimistic, insecure, in characteristic dimension of temperament and harm avoidance, and this inherited readiness makes individuals to show excessive anxiety while facing unfamiliar and stressful situations and stimuli [27].
The results also indicated that there is a positive and significant relationship between characteristic factors of cooperativeness and self-directedness with emotional wellbeing. The results of this research are in line with the findings of Cheng et al [28], Kim et al [29], Sanaat et al [20]. In explaining this finding it can be noted the characteristic dimension of temperament for cooperativeness and selfdirectedness indicates the immaturity and lack of maturation and this can be seen in whom they have not developed self-autonomy, capacity and responsibility in dealing with oneself and others well [30] and also includes the individual's ability in managing their behavior to adapt in new situations and to achieve their goals and values in this way. As a result, patients suffering from cancer are those with week, fragile, critic, ineffective, undeniable characteristic factors and with a tedious, suffering, arrogant, fanatic, blaming behavior. These individuals have a lower understanding of social support and 
show lower skill in confronting challenging situations of life and they further rely on external motivations, therefore, they expose lack of life satisfaction [15], and a low level of these two dimensions justify high levels of temperament from behavioral, impulsivity, anxiety and depression problems in cancer patients and influence their satisfaction [31].

\section{Conclusion}

In conclusion, the findings of this research proved cancer women with characteristic factors of temperament and character have lower emotional wellbeing and as a result, the experience of stressful events in life leads to negative emotions such as anger, anxiety and depression. Since the physical, economical and social problems of cancer is not preventable but for confronting these challenges by providing instruction along with psychological disorders in order to change unhealthy behavioral patterns as well as original physical therapies and reducing harmful variables of characteristic and increasing wellbeing and life quality in the treatment protocol for patients, it is possible to provide a significant help for treatment process of these patients by decreasing harms, promoting health and strengthening the adjustment and adaptation power and to prevent the progression or renewal of the problems and to help these patients in their lives by providing peace, hope and life satisfaction.

I general, it is difficult to provide desirable conditions for conducting a research. The researcher has been faced with some limitations in this research as well, including: Lack of interest from some sample individuals for filling the questionnaire, the low cooperativeness of patients due to physical and psychological conditions, inconsistency conditions of different times (morning, noon, afternoon) and different places (hospital, clinic) to fill the questionnaire. It is advisable to control the intervening variables such as social-economic situations etc. in the subsequent researches and also the experts' presents for analyzing characteristic factors and the way of how patients face the stress in this domain are helpful in determining their psychological health level and applying procedures for its increase and improve.

\section{Acknowledgments}

I respectfully acknowledge the grateful cooperation of my dear colleagues in clinics and hospitals of Semnan province and all patients who contributed in this research with sincere cooperation.

\section{Contributions}

Study design: EP, SK

Data collection and analysis: EP, SK

Manuscript preparation: EP, SK

\section{Conflicts of Interest}

"The authors declare that they have no competing interests."

\section{Funding}

The present study and manuscript were funded entirely by researchers, who received no finance support.

\section{References}

1- Sarafino E. Health psychology: biopsychosocial interactions. Tehran: Growth; 2011.

2- Mousavi SM, Montazeri A, Mohagheghi MA, et al. Breast cancer in Iran: an epidemiological review. Breast J2007; 13(4): 383-91.

3- Jemal A, Bray F, Center MM, Ferlay J, Ward E, Forman D. Global cancer statistics. CA Cancer $J$ Clin2011; 61(2): 69-90.

4- Altschuler A, Rosenbaum E, Gordon P, Canales S, Avins AL. Audio recordings of mindfulness-based stress reduction training to improve cancer patients' mood and quality of life-a pilot feasibility study. Support Care Cancer2012; 20 (6): 1291-7.

5- Bjelic-Radisic V, Jensen PT, Vlasic KK, et al. Quality of life characteristics inpatients with cervical cancer. Eur J Cancer2012; 48(16): 3009-18.

6- Mokhtari M, Nazari J. Sociology quality of life. Tehran: sociologists; 2010.

7- Kaharzayy F, Dansh E, Azadfallah P. The effectiveness of cognitive therapy to improve the quality of life of cancer patients. Journal of Applied Psychology2011; 2(18): 23-7.

8- Diener ED. Guidelines for national indicators of subjective well-being and ill-being. Appl Res Qual Life 2006; 1(2): 151-7.

9- Ng AK, Ho DY, Wong SS, Smith I. In search of the 
good life: A culturalodyssey in the East and West. Genet Soc Gen Psychol Monogr2003; 129(4): 63-317.

10- Keyes C, Lopez S. Toward a Science of mental health: positive direction in diagnosis and interventions. In Snyder $\mathrm{CR}$, Lopez $\mathrm{S}$,eds. The handbook of positive psychology. New York: Oxford University press; 2002. pp: 45-59 11- Millson PE, Challacombe L, Villeneuve PJ, et al. Selfperceived health among Canadian opiate users: a comparison to the general population and to other chronic disease populations. Can J Public Health2004; 95(2): 99-103.

12- Gold M, Dunn LB, Phoenix B, et al. Co-occurrence of anxiety and depressive symptoms following breast cancer surgery and its impact on quality of life. Eur $J$ Oncol Nurs2016; 20: 97-105.

13- Aghayousefi AR, Kharbv A, Hatami H. The role of rumination in wellbeing and anxiety in spouses of cancer patients in Qom province. Journal of Health Psychology Research2015; 14: 79-97.

14- Cloninger CR. A systematic method for clinical description and classification of personality variants. A proposal. Arch Gen Psychiatry1987; 44(6): 573-88.

15- Cloninger CR. Differentiating normal and deviant personality by the seven factor personality model. In Strack S, Lorr M, eds. Differentiating normal and abnormal personality. New York: Springer Publishing Co; 1994.

16- Kaviani H. Biological theories of personality. Tehran: The Sana, Institute of Cognitive Sciences; 2003. pp: 103-47.

17- Cloninger CR, Svrakic DM, Przybeck TR. Personality dimensions as conceptual framework for explaining variations in normal, neuroric, and personality disordered Behavior. in Burrows GD, Noys R, Roth M, eds. Handbook of anxiety, elsevier, Netherlands; 1993.

18- Roy MN. The process of coping in parents of children diagnosed with cancer. [dissertation]. Submitted in partial fulfillment of the requirements for the degree of doctor of philosophy. USD: The University of South Dakota; 2010. 18- Rajabi G. Validation of a Persian version of well-being in cancer patients. Health Psychology2012; 4: 41-30.

19- Quoidbach J, Berry EW, Hansenne M, Mikolajczak M. Positive emotion regulation and well-being: comparing the impact of eight savoring and dampening strategies. Pers Individ Dif2010; 49(5): 368-73.

20- Grami N, Bayrami M, Sanaat Z, Zynayy SH. Examine the relationship between personality dimensions and catching cancer according to Cloninger temperament and character Inventory (TCI). Journal of Medical Sciences 2012; 17: 61-7.

21- Montazeri A, Gashtasebi A, Vahdaninya M. S.trjmh, reliability and validity of Persian standard tool SF-36. Quarterly Monitoring2005; 1: 56-49.

22- Kaviyani H. Validation and hnjarsnjy cloninger temperament and character inventory in Iranian population. Faculty of Tehran University of Medical Sciences 2005; 2(63):89-98.

23- Van Dijck S, Nelissen P, Verbelen H, Tjalma W, Gebruers N. The effects of physical self-management on quality of life in breast cancer patients: A systematic review. Breast2016; 28: 20-8.

24- Hasking PA, Coric SJ, Swannell S, Martin G, Thompson HK, Frost AD. Brief report: emotion regulation and coping as moderators in the relationship between personality and self-injury. J Adolesc2010; 33(5): 767-73. 25- Spittlehouse JK, Pearson JF, Luty SE, et al. Measures of temperament and character are differentially impacted on by depression severity. $J$ Affect Disord2010; 126 (1-2): 140-6.

26- Moradi Msanesh F, Ahadi H, Jomehri F, Rahgozar M. Relationship between Psychological Distress and Quality Of Life in Women with Breast Cancer. Journal of Zabol University of Medical Sciences and Health Services2012; 4(2) :51-9

27- Cloninger CR. A unified biosocial theory of personality and its role in the development of anxiety states. Psychiatr Dev1986; 4(3): 167-226.

28- Cheng QM, Kong CQ, Chang SY, Wei AH. Effects of psychological nursints intervention on personality characteristics and quality of life of patients with esophageal cancer. Clin Res Hepatol Gastroenterol2013; 37(3): 283-8. 29- Kim HW, Cho SC, Kim BM, Shin MS, Yeo JY. Does oppositional defiant disorder have temperament and psychopathological profiles independent of attention deficit/hyperactivity disorder? Compr Psychiatry2010; 51(4): 412-8.

30- Soderstrom H, Rastam M, Gillberg C. Temperament and character in adults with asperger syndrome. Autism 2002; 6(3): 287-97.

31- Biederman J, Petty CR, Dolan C, et al. The longterm longitudinal course of oppositional defiant disorder and conduct disorder in ADHD boys: findings from a controlled 10-year prospective longitudinal follow-up study. Psychol Med2008; 38(7): 1027-35.

\footnotetext{
Copyright(C 2016 ASP Ins. This open-access article is published under the terms of the Creative Commons Attribution-NonCommercial 4.0 International License which permits Share (copy and redistribute the material in any medium or format) and Adapt (remix, transform, and build upon the material) under the Attribution-NonCommercial terms.
} 